\title{
Knowledge and Attitude Toward Strabismus in Western Province, Saudi Arabia
}

Mona S. Khojah ${ }^{1}$, Sarah Al-Ghamdi ${ }^{1}$, Shahad Alaydarous ${ }^{1}$, Jumanah J. Homsi ${ }^{1}$, Ahmed Alhasan ${ }^{2}$, Sara Alsubaie $^{3}$, Nizar Alhibshi ${ }^{4}$

1. Epidemiology and Public Health, King Abdulaziz University, Jeddah, SAU 2. Epidemiology and Public Health, University of Jeddah, Jeddah, SAU 3. Medicine, AlMaarefa University, Riyadh, SAU 4. Ophthalmology, King Abdulaziz University Hospital, Jeddah, SAU

Corresponding author: Mona S. Khojah, mona.khojah@gmail.com

\section{Abstract \\ Background}

Strabismus is a common eye condition having a potential subsequent impact on the psychological and socioeconomic domains of individuals suffering from strabismus. Therefore, this study aimed to find out the level of knowledge and treatability of strabismus in the western province of Saudi Arabia.

\section{Methods}

An observational cross-sectional study was conducted in 2018 among people who live in the western region of Saudi Arabia and were age 16 and above by using an online self-administered questionnaire.

\section{Results}

Out of 589 participants, $52.8 \%$ reported the correct definition of strabismus. The majority of responders agreed that strabismus is treatable (71.5\%). In addition, a statically significant relation was found between knowledge of strabismus treatability and age, gender, work state, and level of education. Most participants were aware of the risk factors and complications of strabismus.

\section{Conclusion}

Our study found that the majority of participants had good knowledge of the definition, treatment, and complications of untreated strabismus. Participant's age, education level, work state, and income were the main factors found to be significantly associated with knowledge of strabismus treatment options.

Received 12/24/2019

Review began 01/02/2020 Review ended 01/04/2020 Published 01/05/2020

\section{() Copyright 2020}

Khojah et al. This is an open access article distributed under the terms of the Creative Commons Attribution License CC-BY 3.0., which permits unrestricted use, distribution, and reproduction in any medium, provided the original author and source are credited.
Categories: Family/General Practice, Ophthalmology, Public Health Keywords: strabismus, subsequent, knowledge, attitude

\section{Introduction}

Strabismus is an ocular condition affecting the alignment of the visual axis, whether caused by abnormalities in binocular vision or anomalies of neuromuscular control of ocular motility [1]. It is commonly called by different names: squint, crossed eyes, deviating eyes, walleyes, goggle eyes, and wandering eyes [2]. The onset of strabismus may vary significantly [3]. The most squints occur in young children [4]. A 2017 study by Torp-Pedersen et al. showed that the prevalence of strabismus at seven years among nearly 100,000 children was $2.56 \%$ [5]. A recent study conducted in 2018 in Arar, Northern Saudi Arabia, reported strabismus in $14.7 \%$ of the studied sample [6].

Amblyopia, loss of vision, and cosmetic stigma are some of the consequences of untreated strabismus [7]. Some studies showed that strabismus is one of the common eye conditions having a potential subsequent impact on the psychological and socioeconomic domains later in the life of individuals suffering from strabismus [8-10], as well as on the effects on their self-image and interpersonal relationships with others, and plays a major role in selecting a partner for adults and in selecting a playmate for children [11-13].

Treatment options usually involve glasses, patching the good eye in case of amblyopia to force the use of the affected eye and surgery to correct the appearance of a squint [14]. Unfortunately, poor parental knowledge about strabismus adversely affects the early presentation and management of the child suffering from strabismus [15].

A study conducted in the Eastern province of Saudi Arabia emphasized the importance of public education and the early detection and management of strabismus to improve the educational opportunities and quality of life of these patients [16]. 
However, in developing countries like Saudi Arabia, there is a paucity of studies that aim to assess the level of knowledge, attitude, and practice of the general community concerning strabismus. Thus, we conducted this study to find out the level of knowledge and attitude towards strabismus in the Western province of Saudi Arabia.

\section{Materials And Methods}

This is an observational, descriptive, cross-sectional study approved by the institutional review board (IRB) of King Abdulaziz University. The study was conducted in 2018 among people who live in Jeddah city, in the western region of Saudi Arabia, by using an online self-administered questionnaire (a Google form) with close-ended questions. The questionnaire was validated by a panel of ophthalmology experts and distributed via a social media platform that is commonly used by the Saudi community such as Twitter, WhatsApp, and others. It was available between June 7, 2018, and June 17, 2018, and filled by the people who agreed to be involved in the study voluntarily. However, we included only participants who were aged 16 and above and living in Jeddah. Those who are medical students and workers or unable to answer the questionnaire due to a language barrier were excluded. The sample size obtained after considering the previous criteria was 589 participants. Their confidentiality was insured, as there was no personal information or identifier collection in the questionnaire.

The survey was composed of multiple-choice questions arranged into two sections. The first one collected demographic data such as age, sex, nationality, educational level, marital status, and economic level. The second section estimated the level of knowledge about strabismus through a number of questions dealing with the definition, risk factors, treatment options, and consequences of the disease on the lifestyle of the patient.

The analysis of the data was done using SPSS (version 25; IBM Corp., Armonk, NY). Qualitative variables were classified according to the aim of the study and then their frequencies and percentages were calculated. To evaluate the relationships between the variables, we used the chi-square test considering that a p-value of $<0.05$ was significant.

\section{Results}

Out of 589 responders to the self-administered electronic questionnaire regarding the community's knowledge of strabismus, 107 (18.2\%) were males and 482 (81.8\%) were females (Table 1). In addition, 42.4\% were younger than 30 years of age and $90.8 \%$ were Saudi. Regarding socioeconomic status, $63.3 \%$ were married, $78.1 \%$ were highly educated, $43.3 \%$ were office workers, and $45.7 \%$ were from the medium-income class. 


\section{Cureus}

\begin{tabular}{|c|c|c|c|}
\hline \multicolumn{2}{|l|}{ Variable } & Frequency & Percent (\%) \\
\hline \multirow{3}{*}{ Age } & $16-30$ years & 250 & 42.4 \\
\hline & $31-45$ years & 215 & 36.5 \\
\hline & 46 years and older & 124 & 21.1 \\
\hline \multirow{2}{*}{ Gender } & Male & 107 & 18.2 \\
\hline & Female & 482 & 81.8 \\
\hline \multirow{2}{*}{ Nationality } & Saudi & 535 & 90.8 \\
\hline & Non-Saudi & 54 & 9.2 \\
\hline \multirow{4}{*}{ Marital Status } & Married & 373 & 63.3 \\
\hline & Single & 183 & 31.1 \\
\hline & Divorced & 25 & 4.2 \\
\hline & Widowed & 8 & 1.4 \\
\hline \multirow{3}{*}{ Educational Level } & Illiterate & 4 & .7 \\
\hline & Diploma or less & 125 & 21.2 \\
\hline & Bachelor or more & 460 & 78.1 \\
\hline \multirow{6}{*}{ Work } & Office worker & 255 & 43.3 \\
\hline & Free worker & 12 & 2.0 \\
\hline & Housemaid & 107 & 18.2 \\
\hline & Retired & 36 & 6.1 \\
\hline & Student & 139 & 23.6 \\
\hline & None & 40 & 6.8 \\
\hline \multirow{3}{*}{ Income } & Low income (<5000 SAR) & 139 & 23.6 \\
\hline & Medium income (5000-10000 SAR) & 269 & 45.7 \\
\hline & hHgh income (>10000 SAR) & 180 & 30.6 \\
\hline Missing & & 1 & 0.2 \\
\hline Total & & 589 & 100.0 \\
\hline
\end{tabular}

TABLE 1: Demographic data of survey responders

Among responders, only 38 (6.5\%) had a child of their own who was diagnosed with strabismus while 37

(6.3\%) had a child who was treated for strabismus. However, 224 (38\%) of them admitted to having a relative with strabismus (Table 2). 


\section{Cureus}

\begin{tabular}{|c|c|c|c|}
\hline & & Frequency & Percent (\%) \\
\hline \multirow{4}{*}{ A child who is diagnosed with a squint } & Yes & 38 & 6.5 \\
\hline & No & 368 & 62.5 \\
\hline & I do not know & 14 & 2.4 \\
\hline & not applied & 168 & 28.5 \\
\hline \multirow{4}{*}{ A child who is treated for a squint } & Yes & 37 & 6.3 \\
\hline & No & 388 & 65.9 \\
\hline & I do not know & 5 & .8 \\
\hline & Not applied & 158 & 26.8 \\
\hline \multirow{3}{*}{ A family member who has a squint } & Yes & 224 & 38.0 \\
\hline & No & 316 & 53.7 \\
\hline & I do not know & 48 & 8.1 \\
\hline Missing & & 1 & .2 \\
\hline Total & & 589 & 100.0 \\
\hline
\end{tabular}

\section{TABLE 2: Social experience with strabismus among survey responders}

In assessing knowledge of the strabismus definition, 52.8\% of responders chose eye deviation as a definition while $33.4 \%$ chose to define it as abnormal eye movements (Table 3). However, there was no statistically significant relationship with gender, age, nationality, education, or socioeconomic state.

\begin{tabular}{|c|c|c|c|}
\hline & & Frequency & Percent (\%) \\
\hline \multirow{5}{*}{ Knowledge of squint definition } & Deviation of eye/s & 311 & 52.8 \\
\hline & Abnormal movement of eye/s & 197 & 33.4 \\
\hline & do not know & 52 & 8.8 \\
\hline & Deviation and abnormal movement of eye/s & 28 & 4.8 \\
\hline & Total & 588 & 99.8 \\
\hline Missing & & 1 & .2 \\
\hline
\end{tabular}

\section{TABLE 3: Knowledge of strabismus definition among survey responders}

Regarding knowledge of strabismus treatment, the majority of responders agreed that strabismus is treatable, with $71.5 \%$ choosing yes (Table 4). Importantly, eye surgery, eye lenses, and eye patches were all chosen as possible treatment options, with $14.9 \%, 11.2 \%$, and $5.4 \%$, respectively (Table 5). However, 37\% thought that all choices are possible treatment options for strabismus. In addition, a statically significant relation was found between knowledge of strabismus treatability and age, gender, and work state $(\mathrm{p}=000$, 042 , and 045 , respectively). In the same way, a statically significant relation was found between knowledge of strabismus treatment options and age, educational level, work state, and income ( $\mathrm{p}=001,011,017$, and 002, respectively). 


\section{Cureus}

\begin{tabular}{|c|c|c|c|}
\hline & & Frequency & Percent (\%) \\
\hline \multirow{4}{*}{ Knowledge of the treatability of a squint } & Yes & 421 & 71.5 \\
\hline & No & 30 & 5.1 \\
\hline & I do not know & 137 & 23.3 \\
\hline & Total & 588 & 99.8 \\
\hline Missing & & 1 & .2 \\
\hline
\end{tabular}

TABLE 4: Knowledge of the treatability of strabismus among survey responders

\begin{tabular}{|c|c|c|c|}
\hline & & Frequency & Percent (\%) \\
\hline \multirow{9}{*}{ Knowledge of treatment options for squint } & Glasses or contact lenses & 66 & 11.2 \\
\hline & Eye patches & 32 & 5.4 \\
\hline & Eye surgery & 88 & 14.9 \\
\hline & Glasses and patches & 9 & 1.5 \\
\hline & Glasses and surgery & 25 & 4.2 \\
\hline & Eye patches and surgery & 12 & 2.0 \\
\hline & All are choices & 218 & 37.0 \\
\hline & I do not know & 138 & 23.4 \\
\hline & Total & 588 & 99.8 \\
\hline Missing & & 1 & .2 \\
\hline
\end{tabular}

TABLE 5: Knowledge of treatment options for strabismus among survey responders

Additionally, the most frequently reported risk factors to develop strabismus from the responders' point of view were family history (16\%) and eye refractive errors (12.9\%) (Table ๑). From the responders' point of view too, frequent complications of untreated strabismus were visual loss (4.6\%), cosmetic stigma (3.9\%), and poor self-image (2.4\%); however, a clear majority chose "All of the above" with 55.2\% (Table 7). 


\section{Cureus}

\begin{tabular}{|c|c|c|c|}
\hline & & Frequency & $\begin{array}{l}\text { Percent } \\
\text { (\%) }\end{array}$ \\
\hline \multirow{20}{*}{$\begin{array}{l}\text { Knowledge of risk factors to develop a } \\
\text { squint }\end{array}$} & Family history & 94 & 16.0 \\
\hline & Eye refractive errors (nearsightedness, farsightedness, and astigmatism) & 76 & 12.9 \\
\hline & Systemic diseases (Down's syndrome, cerebral palsy...) & 8 & 1.4 \\
\hline & Low socioeconomic state & 0 & 0.0 \\
\hline & Smoker mother & 0 & 0.0 \\
\hline & $\begin{array}{l}\text { Family history, systemic diseases, low socioeconomic state, and smoker } \\
\text { mother }\end{array}$ & 1 & .2 \\
\hline & Family history, systemic diseases, and smoker mothers & 4 & .7 \\
\hline & Eye refractive errors, systemic diseases, and smoker mothers & 1 & .2 \\
\hline & $\begin{array}{l}\text { Family history, eye refractive errors, systemic diseases, and smoker } \\
\text { mothers }\end{array}$ & 3 & .5 \\
\hline & Family history and smoker mother & 1 & .2 \\
\hline & Family history and eye refractive errors & 46 & 7.8 \\
\hline & Family history and systemic diseases & 25 & 4.2 \\
\hline & Eye refractive errors and systemic diseases & 5 & .8 \\
\hline & Family history, eye refractive errors and systemic diseases & 33 & 5.6 \\
\hline & Family history, eye refractive errors and smoker mothers & 2 & . 3 \\
\hline & systemic diseases and smoker mothers & 1 & .2 \\
\hline & All of the above & 54 & 9.2 \\
\hline & Nothing of the above & 25 & 4.2 \\
\hline & I do not know & 210 & 35.7 \\
\hline & Total & 589 & 100.0 \\
\hline
\end{tabular}

TABLE 6: Knowledge of risk factors to develop strabismus among survey responders 


\section{Cureus}

\begin{tabular}{|c|c|c|c|}
\hline & & Frequency & $\begin{array}{l}\text { Percent } \\
(\%)\end{array}$ \\
\hline \multirow{17}{*}{$\begin{array}{l}\text { Knowledge of the complications of an untreated } \\
\text { squint }\end{array}$} & Visual loss (partial or complete) & 27 & 4.6 \\
\hline & Poor self-image & 14 & 2.4 \\
\hline & Poor interpersonal relationships & 5 & .8 \\
\hline & Cosmetic stigma & 23 & 3.9 \\
\hline & Poor self-image, interpersonal relationships, and appearance & 23 & 3.9 \\
\hline & Visual loss, poor self-image, and interpersonal relationships & 2 & .3 \\
\hline & Visual loss and poor self-image & 3 & .5 \\
\hline & Poor self-image and interpersonal relationships & 3 & .5 \\
\hline & Visual loss and cosmetic stigma & 10 & 1.7 \\
\hline & Poor self-image and appearance & 11 & 1.9 \\
\hline & Visual loss, poor self-image, and appearance & 3 & .5 \\
\hline & Poor interpersonal relationships and appearance & 10 & 1.7 \\
\hline & $\begin{array}{l}\text { Visual loss, poor interpersonal relationships, and } \\
\text { appearance }\end{array}$ & 3 & .5 \\
\hline & All of the above & 325 & 55.2 \\
\hline & Nothing of the above & 14 & 2.4 \\
\hline & I do not know & 113 & 19.2 \\
\hline & Total & 589 & 100.0 \\
\hline
\end{tabular}

TABLE 7: Knowledge of the complications of untreated strabismus among survey responders

With respect to the community's awareness of strabismus as a health problem, $471(80 \%)$ responders thought that strabismus treatment is a must for any age.

\section{Discussion}

The study aimed to assess the knowledge of diagnosis and treatability of strabismus in the Western province, KSA. The identification and treatment of strabismus at an early age can lead to a better prognosis. Consequently, a lack of knowledge among parents and the population adversely affects the early diagnosis and management of strabismus [17].

The most obvious finding to emerge from the analysis is that the older workers with a good income and higher educational level have a better knowledge of strabismus treatability and treatment options. Also, $71.5 \%$ of the whole population knows that strabismus can be treated. This result is inconsistent with a study that took place in Nigeria, as $54 \%$ of the population did not know that strabismus can be treatment and only $21 \%$ knew about a medical treatment option. These results are likely related to the educational level where $22 \%$ of the Nigerian population in the previous study are illiterate [18].

The results of this study do not show any significant relationship between the knowledge of the definition of strabismus and gender, age, nationality, education, or socioeconomic status. This outcome is contrary to that of Isawumi et al., who found that women were more knowledgeable than men about strabismus, while there was no significant relationship to age [18]. This result likely related to the higher percentage of educated participants in our study (78.1\%).

In the present study, most of the participants are aware of the risk factors of strabismus. The most frequently reported risk factors to develop strabismus are family history and eye refractive errors. However, other works of literature found that hereditary factors and ocular diseases are the most common risk factors for strabismus [18-19].

In our study, frequent complications of untreated strabismus are visual loss (4.6\%), cosmetic stigma (3.9\%), 
and poor self-image, and the majority chose "All of the above." Other studies showed that 95\% of participants reported psychological complications regardless of the type of strabismus [20]. A cross-sectional study done in India found that children with strabismus had difficulty in making friends and finding a job [17]. The results reported by Ziaei et al. support this result; they found a positive improvement in the physical and psychological functions of children who were treated surgically for strabismus [21]. Additionally, strabismus had other vision-related complications, which could lead to an economic burden [19].

In this study, we faced several limitations regarding the distributed survey through different channels of social media. One of them was that the survey might not have been distributed enough to cover all the different social classes of the population. In addition, the study was restricted to the western region of Saudi Arabia; thus, it could not be filled by someone outside this region. Therefore, we recommend conducting the study among all Saudi Arabian residents.

\section{Conclusions}

Our study found that more than half of the studied sample had good knowledge of the definition and complications of untreated strabismus, and the majority of participants agreed that strabismus is a treatable disease. Participant's age, education level, work state, and income were the main factors found to be significantly associated with knowledge of the treatment options of strabismus. Overall, the level of awareness of strabismus was high and that is very important because previous knowledge of the disease may reduce the delays in seeking medical care, and this would reduce visual impairment and economic burden in the society. We recommend more public health education and to increase further awareness in all provinces of Saudi Arabia and to conduct other studies about amblyopia as a serious complication of untreated strabismus, which can lead to visual loss.

\section{Additional Information \\ Disclosures}

Human subjects: All authors have confirmed that this study did not involve human participants or tissue. Animal subjects: All authors have confirmed that this study did not involve animal subjects or tissue. Conflicts of interest: In compliance with the ICMJE uniform disclosure form, all authors declare the following: Payment/services info: All authors have declared that no financial support was received from any organization for the submitted work. Financial relationships: All authors have declared that they have no financial relationships at present or within the previous three years with any organizations that might have an interest in the submitted work. Other relationships: All authors have declared that there are no other relationships or activities that could appear to have influenced the submitted work.

\section{Acknowledgements}

The authors acknowledge Tassenim Om Alola M. Almairi.

\section{References}

1. Simon JW, Buckley EG, Drack AV, Hutchinson AK, Plager DA, Raab EL: Basic and Clinical Science Course. Section 6. 2005-2006, Pediatric Ophthalmology and Strabismus. American Academy of Ophthalmology, San Francisco, CA; 2005.

2. Brodsky M, Baker R, Hamed L: Pediatric Neuro-Ophthalmology. Springer Verlag, New York; 1996.

3. Bui Quoc E, Milleret C: Origins of strabismus and loss of binocular vision . Front Integr Neurosci. 2014, 8:71. 10.3389/fnint.2014.00071

4. Pathai S, Cumberland P, Rahi J: Prevalence of and early-life influences on childhood strabismus. Findings from the Millennium Cohort Study. Arch Pediatr Adolesc Med. 2010, 164:250-257. 10.1001/archpediatrics.2009.297

5. Torp-Pedersen T, Boyd H, Skotte L, Haargaard B, Wohlfahrt J, Holmes J, Melbye M: Strabismus incidence in a Danish population-based cohort of children. JAMA Ophthalmol. 2017, 135:1047-1053. 10.1001/jamaophthalmol.2017.3158

6. Alenezi H, Abo El-Fetoh N, Alruwaili A, et al.: Squint in children and adolescents, Arar, Northern Saudi Arabia. Egypt J Hosp. 2018, 70:298-302. 10.12816/0043093

7. Geta K, Bejiga A: Knowledge, attitude and practice towards strabismus in Cheha District, Central Ethiopia . Ethiop J Health Dev. 2011, 25:212-215.

8. Uretmen O, Egrilmez S, Kose S, Pamukçu K, Akkin C, Palamar M: Negative social bias against children with strabismus. Acta Ophthalmol Scand. 2003, 81:138-142. 10.1034/j.1600-0420.2003.00024.x

9. Olitsky SE, Sudesh S, Graziano A, Hamblen J, Brooks SE, Shaha SH: The negative psychosocial impact of strabismus in adults. J AAPOS. 1999, 3:209-211. 10.1016/s1091-8531(99)70004-2

10. Satterfield D, Keltner J.L, Morrison TL: Psychosocial aspects of strabismus study. Arch Ophthalmol. 1993, 111:1100-1105. 10.1001/archopht.1993.01090080096024

11. Menon V, Saha J, Tandon R, Mehta M, Khokhar S: Study of the psychosocial aspects of strabismus . J Pediatr Ophthalmol Strabismus. 2002, 39:203-208.

12. Mojon-Azzi SM, Potnik W, Mojon DS: Opinions of dating agents about strabismic subjects' ability to find a partner. Br J Ophthalmol. 2008, 92:765-769. 10.1136/bjo.2007.128884

13. Johns HA, Manny RE, Fern KD, Hu YS: The effect of strabismus on a young child's selection of a playmate . 


\section{Cureus}

Ophthalmic Physiol Opt. 2005, 25:400-407. 10.1111/j.1475-1313.2005.00310.x

14. Royal College of Ophthalmologists. Guidelines for the management of strabismus in childhood . (2012). Accessed: December 1, 2019: https://www.rcophth.ac.uk/wp-content/uploads/2014/12/2012-SCI-250Guidelines-for-Management-of-Strabismus-in-Childhoo....

15. Eustis S, Smith DR: Parental understanding of strabismus. J Pediatr Ophthalmol Strabismus. 1987, 24:232236.

16. Al-Tamimi ER, Shakeel A, Yassin AS, Ali SI, Khan UA: A clinic-based study of refractive errors, strabismus, and amblyopia in pediatric age-group. J Family Community Med. 2015, 22:158-162. 10.4103/22308229.163031

17. Singh A, Rana V, Patyal S, Kumar S, Mishra SK, Sharma VK: To assess knowledge and attitude of parents toward children suffering from strabismus in Indian subcontinent. Indian J Ophthalmol. 2017, 65:603-606. 10.4103/ijo.IJO 61916

18. Isawumi MA, Ulaikere M, Adejumo OO, Adebayo M, Kekunnaya R: Awareness, perceptions and knowledge of strabismus among patients visiting a tertiary eye clinic in Southwest Nigeria. Int Ophthalmol. 2014, 34:1037-1042. 10.1007/s10792-014-9902-3

19. Bukhari D, Alhibshi N, Alzahrani N, Aljohani M, Madani F: Awareness, perceptions and knowledge of strabismus among pediatrics and ophthalmology clinics attendees in King Abdulaziz University Hospital, Jeddah. Ann Int Med Den Res. 2018, 4:12-19. 10.21276/aimdr.2018.4.2.OT4

20. Enzenauer RW: Strabismus repair is not “cosmetic". J Pediatr Ophthalmol Strabismus. 1994, 31:67.

21. Ziaei H, Katibeh M, Mohammadi S, et al.: The impact of congenital strabismus surgery on quality of life in children. J Ophthalmic Vis Res. 2016, 11:188-192. 10.4103/2008-322X.183918 